\title{
EVOLUTION OF SPORTS AND THEIR ARCHITECTURAL STRUCTURES AND COMPLEXES
}

\author{
Roshini Pushparaj \\ Student (10 $0^{\text {th }}$ Semester), PES University, INDIA, roshini.h.pushparaj@gmail.com
}

\begin{abstract}
Sports, as an industry has had a very unique evolution; for it evolved from bread-winning activities and became an entity of its own. Owing to its longstanding history in human evolution, starting from natural needs like the hunting-gathering of the early man. Sports were introduced to test their abilities for different activities after the popularization of agriculture and cultivation for the source of food.

The addition of monetary or tangible winnings and prediction-based bets to the rule-defined test of skill has evolved to today's sports industry, with the inception of our current day stadiums and complexes.

Owing to the rich history we see in correlation to sports and entertainment; this study will be focusing on how impactful the norms and practices of those times were towards the building of sports complexes and stadiums. The parameters to be explored are: The capacity of the Area/Complex, Socio-economic impact, Glamour vs. Quality Essentials, Purpose of Stadium after the Sports Events, and Change over Time.

Structures have greatly contributed to the exhibition of emperors, the portrayal of the sport itself, the evolving needs of the patrons, and in most cases even contribute to revolutions lead by the practices of sports in time. These particulars aid in understanding and maintaining the sanctity of sports in the future sports structures' development and also understand the root cause of standard practices.

The study looks to understand the needs and demands of sports over time and how the complexes have facilitated it time and again. It provides an overview of how these spaces account for more than their intended purpose, coming through during crisis and augmenting society. This understanding allows us to analyze user patterns over time and provide a seamless space and experience for the patrons of various sports.
\end{abstract}

Keywords: Sport Evolution, Socio-economic impact, Sports Structures, Multi-purpose spaces, Public Spaces

\section{INTRODUCTION}

Sports have a longstanding history in human evolution, starting from natural needs like the hunting-gathering of the early man. A more defined need for competitive skills arose at the change of the dominant mode of food sourcing, the popularization of farming. Earlier hunters were physically fit, but opportunities to exhibit their skill became redundant.

So, sports were introduced to test their abilities for different activities (including hunting), such as speed 
through races (further assessing their ability to run errands), strength while wrestling (further evaluating their ability to do the heavy lifting for cultivation or construction), archery and spear throwing skills (for hunting), swimming (for fishers), etc. As seen in Fig. 1 and 2, this is prominent across various cultures.

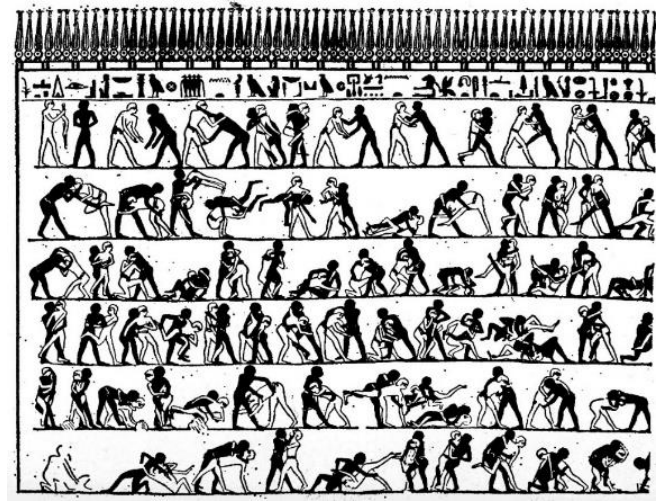

Fig. 1: Egyptian mural depicting wrestlers in action (Source: Newspaper clipping, "Hufvudstadsbladet", Helsinki, Finland, published 1972-01-22)

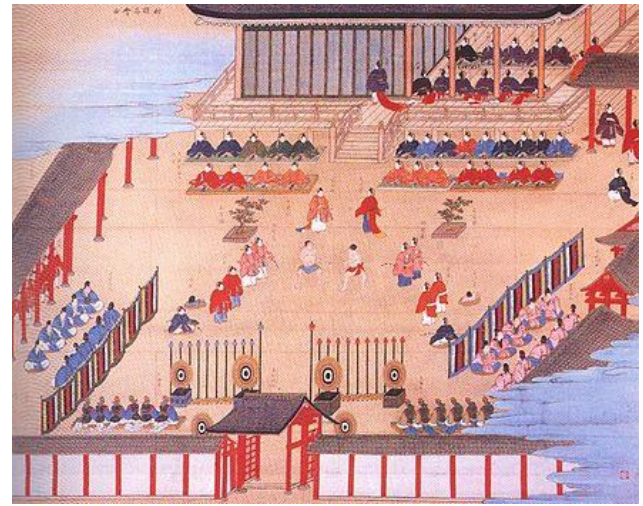

Fig. 2: Ancient Sumo Wrestling Competition (Source: Pacific University Asian Studies Pacific University Asian Studies)

This, alongside monetary or tangible winnings and prediction-based bets, has evolved to today's sports industry. However, the sporting culture of then involved a lot of grit and chaos, which demanded the right setting and barricades to maintain decorum, the genesis of our current day stadiums and complexes. Fig. 3 gives a brief timeline to this evolution.

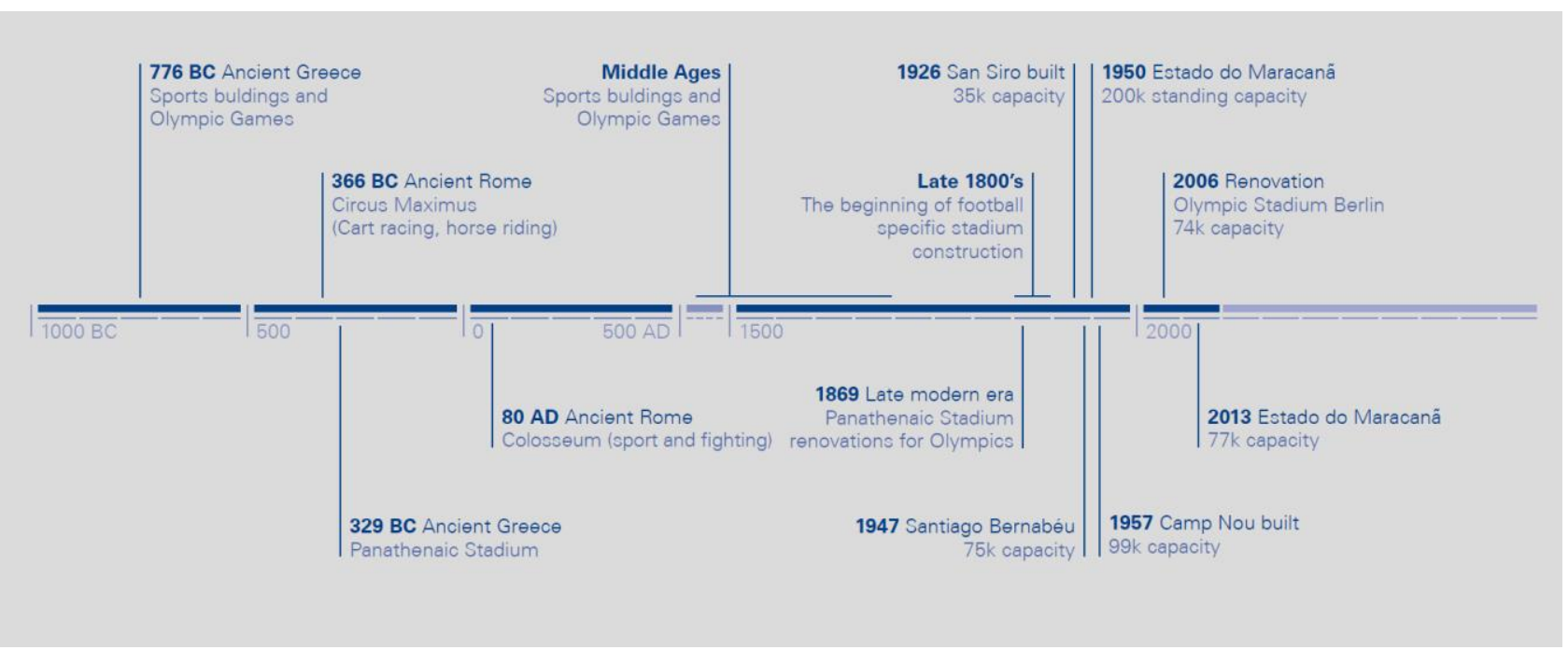

Fig. 3: Timeline of Revolutionary Sports Structures developed around the world (Source: KPMG Sports Advisory)

This study looks to understand what were the needs demands of sports over time and how the complexes have facilitated it time and again. This understanding allows us to provide a seamless space for the user experience of patrons of various sports.

This evolution of sports and the parallel evolution of its structures can be understood through these 5 parameters:

\subsection{Capacity of the Area/Complex}

The capacity of the sporting area or complex contributes to many aspects of sports. It tells us about the popularity of the sport, the right or privilege associated with it, and like seen in golf, it also indicates if a sport is a crowd-pleaser or an acquired taste. 
In the older days, before rules and guidelines were determined upon, most sporting events were children's recreation or, in extreme cases, illegal brawling. As seen in Fig. 4, there was always a crowd that encompasses the entertainment and amusement. It allowed the people a momentary break from their daily lives. Slowly the technique and quick-thinking involved were appreciated, allowing brokers and managers to make a living out of it. People were hired to fight and bets were placed upon them. More defined settings like the harbor or the mining areas were chosen and these fights were scheduled at particular times.

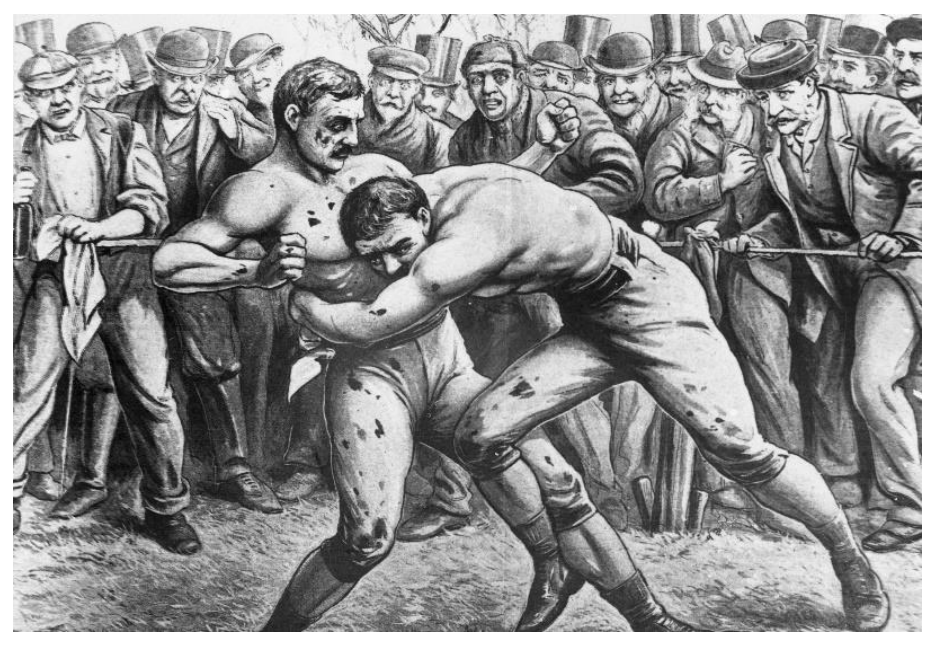

Fig. 4: Bare knuckles boxing match, circa the 1860s (Source: Rischgitz/Getty Images)

The capacity of the spaces was limiting with the growing popularity of many sports, and hence dedicated spaces were constructed to facilitate events of this nature.

There are exceptions though, especially for sports like football and cricket. These sports, though originating from secluded clans like Chinese or the early Saxons, they were popularized by the British. They adopted rough versions of these games and defined them with rules. But it was always formalized to be games of the higher classes. It was played in their boarding schools and colleges and inter-collegiate tournaments were arranged. The viewership, however, included a larger audience. But restricted their ability to take part in the action to just auditory communication, like the commentary on radios and delayed information through printed media.

It always left the larger audience with a lack of achievability, for kids of the poorer community 'aspired' to play the game, rather than enjoy it, as seen in Fig. 5. And the viewers of the live matches were the affluent upper classes.

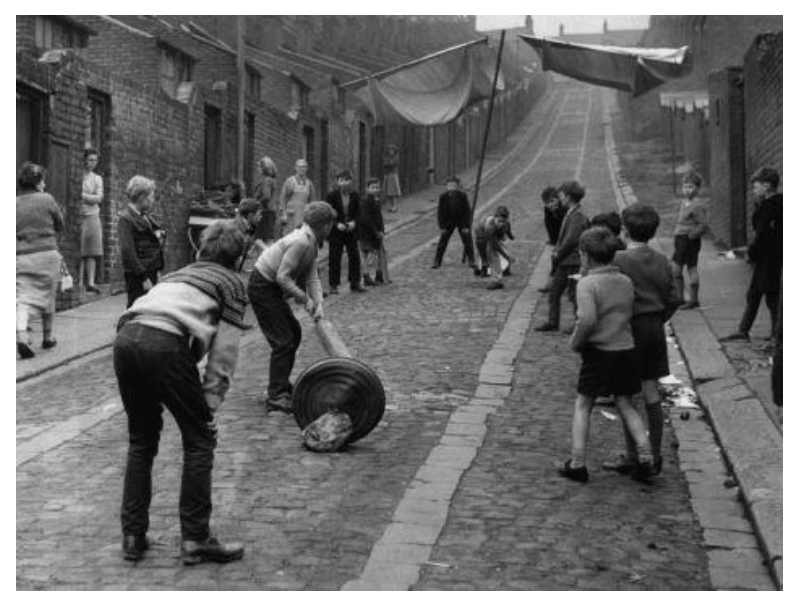

Fig. 5: Children Playing Cricket in the Back Streets of Newcastle, 1962 (Source: Pinterest)

\subsection{Socio-economic impact}

Such scenarios contribute to the social strata. A sport can divide or bridge the ever-growing gap between classes. Older times allowed the rich and affluent to be born into their privilege. Though capitalism existed, they were always hereditary and generations of occupation-based decisions. 
The rich owned the banks and the lands. Not only could they afford to set aside time to practice and be good at the game (unlike the poor who lived by their daily wages), they could also contribute to the preparation of the events and the effort of grandeur achieved there.

It allowed them to dedicate lush and manicured fields and also employ dedicated maintenance of these fields. Quality infrastructure for the viewer stands, team uniforms to portray their fealty to their respective teams, and even awards and trophies. Fig. 6 shows one such instance.

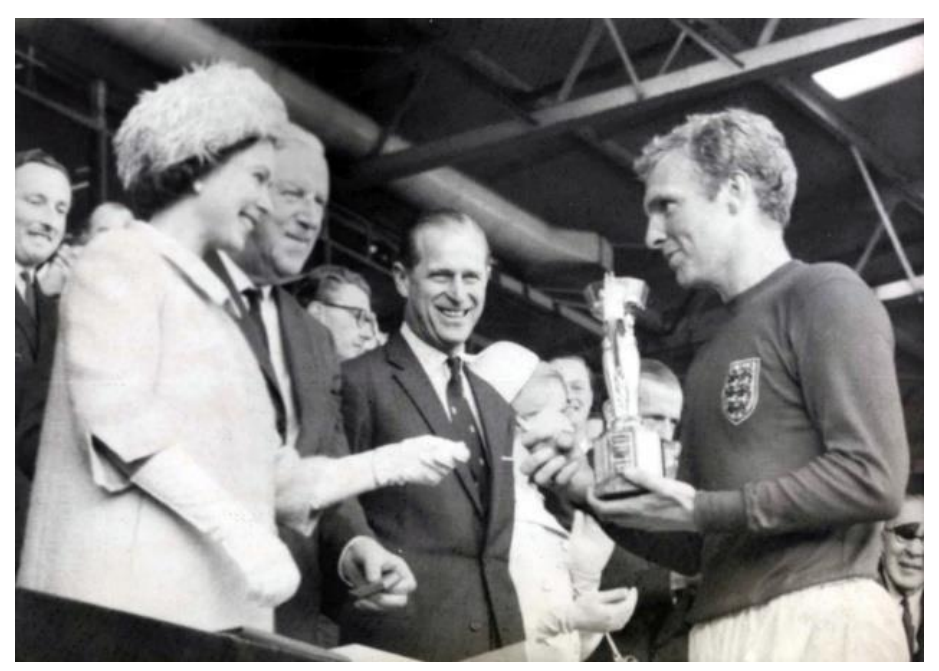

Fig. 6: The Queen presents the 1966 World Cup to England Captain, Bobby Moore (Source: Daily Herald Archive at the National Media Museum)

Today's world of football, however, is not exclusive. It is rather a world-popular sport and the credit goes to the lower class of England and Scotland. Players were hired by mill owners to train exclusively in the sport, the birth of professional league players. Though initially met with great resistance by the upper classes for tarnishing the sanctity of the game, the growing popularity of these players due to the working-class audience rooting for the win of a fellow member, enabled more mill owners to consider professional players.

Newer federations cropped up and soon these teams were celebrated for better skill and finesse of the game, allowing the professional players to earn a great income. This bridged the class divide quicker than any other method seen in the olden times, even allowing people to consider careers and occupations outside the ones they were born into.

\subsection{Glamour vs. Quality essentials}

The popularity of such games did not just stop with more money being paid to see the players. The people thrived on the drama and exaggeration that came with the games. There was always a certain spike in energy associated with it and all the more pride the patrons felt, to see them in their flag colors, patrons donning the same in support and various ways visuals aiding to it, what we now call brand image.

This practice, although, has been observed from ancient times, where the Kings arranged grand feasts and celebrations in preparation for wars and combats. In earlier days, the larger stadiums were built for kings to interact with their subjects and make public appearances through the form of blood games. The later stadia, however, were focused on accommodating the growing audience.

What both have in common for the recreational priorities is the need for the glamour quotient.

There were always sides chosen; providing strong support for both teams, however high or low their chances of winning were. More often than not, glamour was also used to raise awareness of new events and committees about sports. Fig. 7 illustrates this in great detail. 


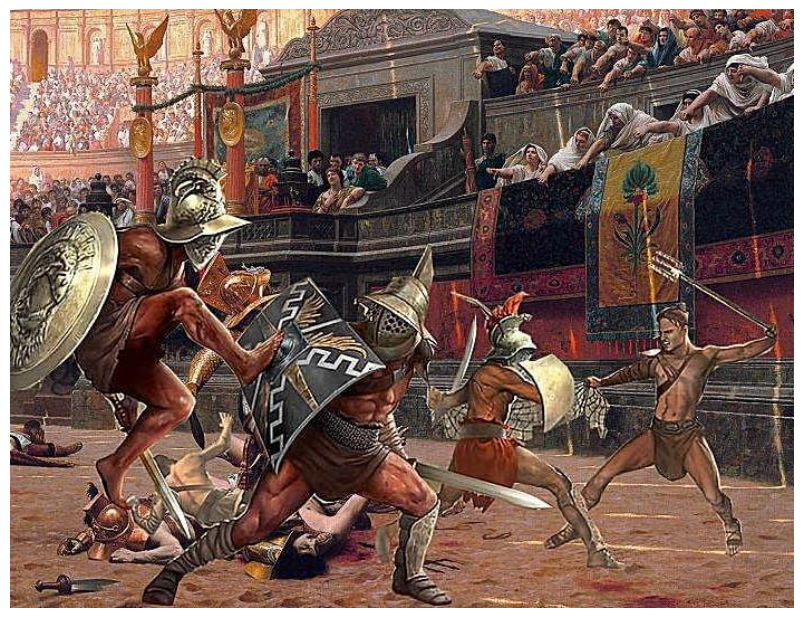

Fig. 7: Three kinds of gladiators fighting in the Colosseum before the Emperor and the Vestal Virgins (Source: https://www. atouchofrome.com/colosseum.html)

This, however, never interfered with the fundamental purpose of the space, which was in the dedication of the sport. Sports of any era, the standard areas were maintained, even indicating the origin of today's norm and standards we see for the Olympic and other international games.

These spaces were slowly converted to become multi-purpose, as the boundaries were sufficient to maintain the game. Larger pitches and grounds allowed the buildings to be planned for larger audiences and the fields were designed, keeping in mind the larger limits required. This added to the majestic outlook of the spaces, maintaining the essential requirements at the premium quality the sponsors and donors could allow.

\subsection{Purpose of Stadiums after the Sports events}

While we discuss the multipurpose nature of the larger spaces, we also observe these spaces being used for other socio-economic reasons.

A lot of Colosseum's history comes from just the Roman era and the past hundred years of documented history and conservation. It was discovered during that the Roman inhabitants, when found no use for space, would take away chunks of its built form (such as the metal pins and marbles) to re-purpose it in an attempt to avoid great transport cost of materials. Although, that only contributes to a fraction of the narrative, for it remained upright all these years, though battered and broken.

During the medieval years, the arena was converted to small houses and workshops, roughly using each vaulted area as a unit of calculation for as long as 1200 AD. Not just that, but these spaces were majorly used as refuge areas, makeshift hospitals, and rehabilitation centers for the wounded in the war, as seen in Fig. 8. The large capacity of these spaces proved to be ideal for the number of people wounded, and the range of visibility ensured that warriors were prepared for further attacks.

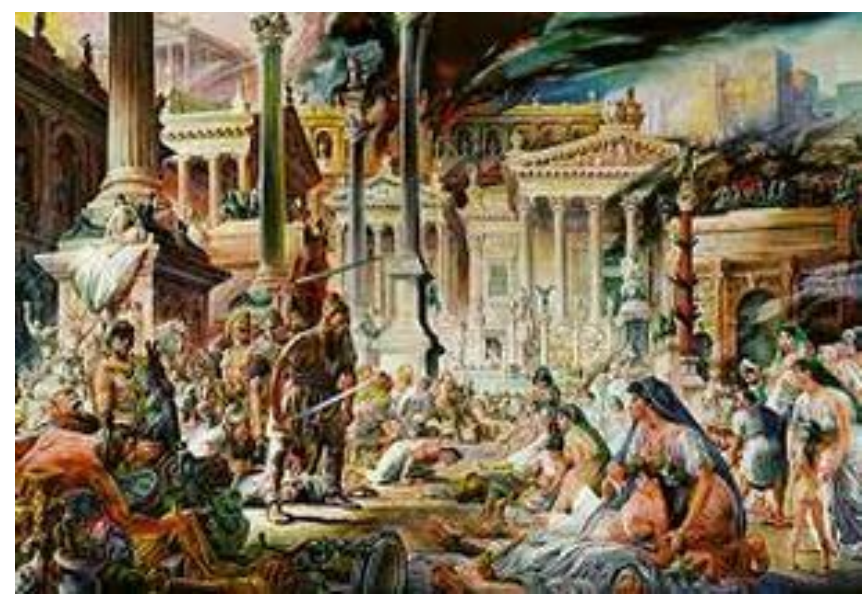

Fig. 8: Rome in the Dark Ages, through war and refuge (Source: https://darkagesproject65.weebly.com/medieval-life--society.html) 
Fig. 9 shows that this trend remains during WW1 and WW2. As most large structures are found in the then cities, which are also the major political hubs throughout time, they have faced constant attacks. Medics were stationed behind temporary structures and in dire need of intense medication, the wounded were transported to such structures.

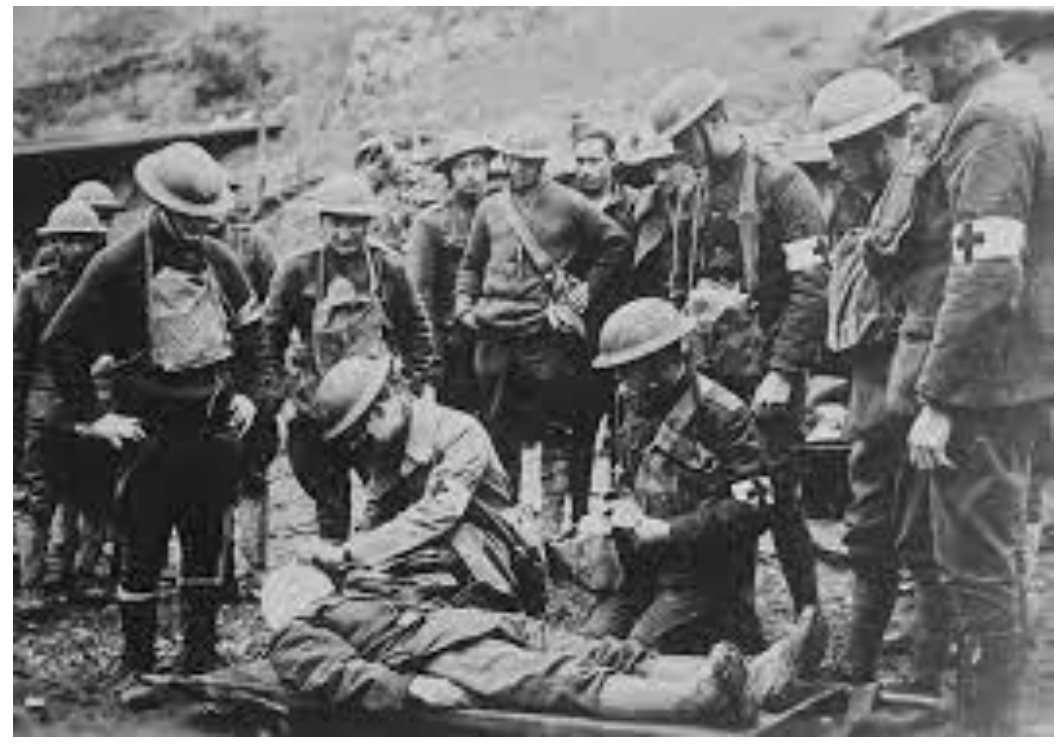

Fig. 9: Medicine in the war zone during WW1 (Source: https://www.historyplace.com/worldhistory/firstworldwar/us-head-wound.htm)

As the end of the $20^{\text {th }}$ century saw quieter times - focused on technological growth and advancement in the sciences - the early $21^{\text {st }}$ century purposes large sports structures to house music concerts and live gatherings, a source of revenue for sports organizations. A stadium's multi-purpose tendencies, however, do not just stop there.

The Pandemic due to Covid-19 shot up as early as March 2020 and the panic and inadequacy of treatment facilities were also tackled due to the large spaces being converted to a temporary health facility (Fig. 10).

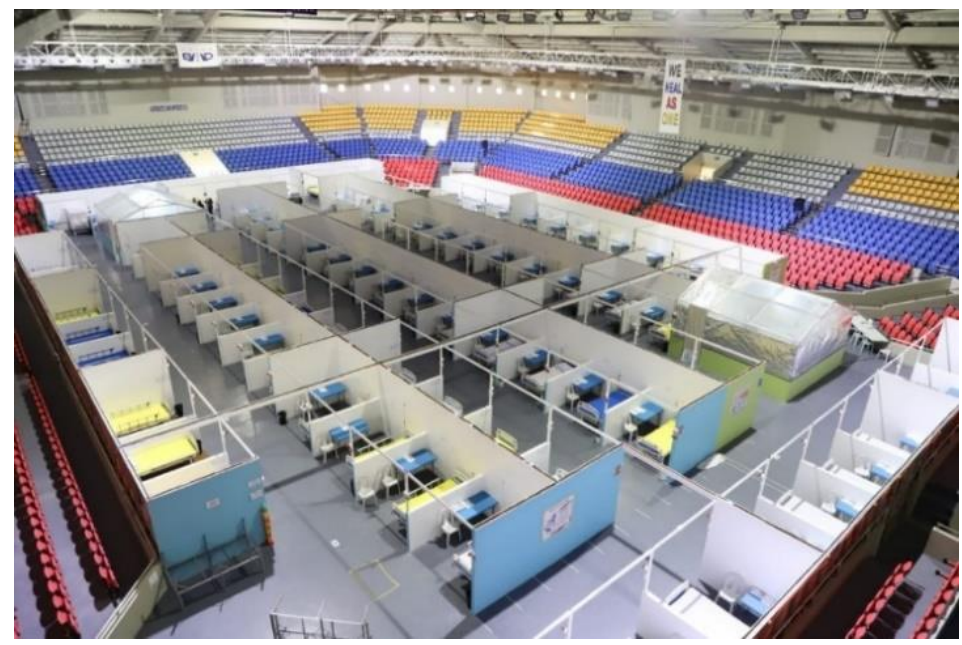

Fig.10: The Ninoy Aquino Stadium refurbished as a health facility in the Philippines (Source: Philippine Information Agency)

\subsection{Change over Time}

Applicable for structures that have withstood time, it does prove relevant to observe those attributes that have contributed to it. More often than not, chance or luck does play a role, for if not we would not have lost a majority of the northern Hindu Architecture to the Mughal Invasions. 
Major powers and influences over time have been the reason for the safekeeping of large public spaces like stadiums. Taking the instances of the Colosseum, where the Colosseum came under the possession of the Church, who preserved and contributed to the intact status of the structure for more than a millennium.

Fig. 11 and 12 shows that even structures like the Epidaurus have natural phenomena to their aid. The remote nature of this Greek city allowed very little damage due to man's actions and in addition to that, a landslide had covered the entire theatre, allowing it to be excavated with little to no damage. It still holds its acoustic properties and can function as before.

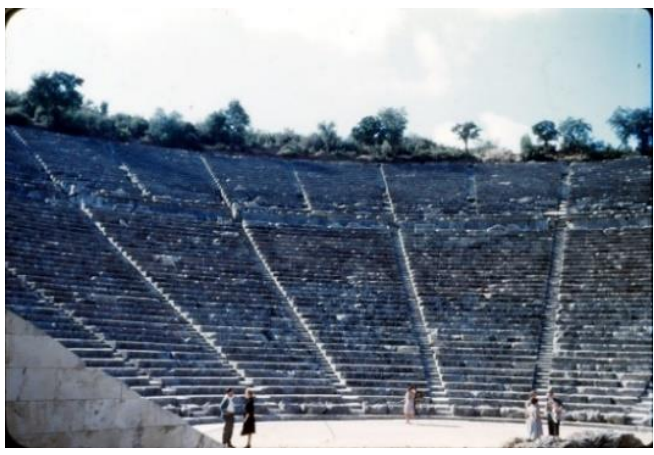

Fig. 11: Epidaurus in the 1960s (Source: J. https://travel-addict.net)

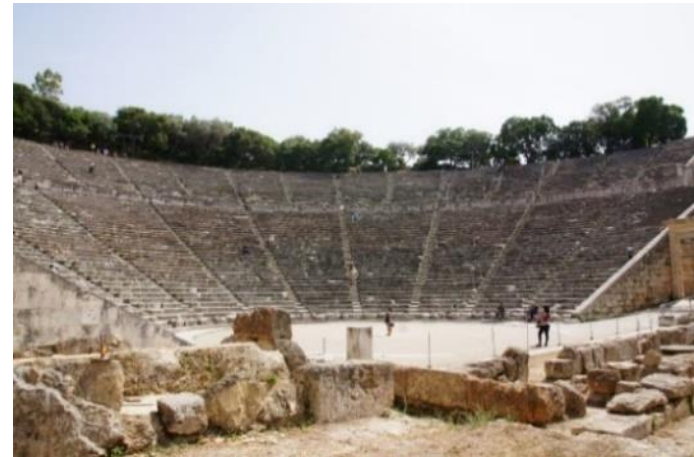

Fig. 12: Epidaurus in the 21st century (Source: J. https://travel-addict.net)

Usage of space is a very specific combination of maintenance and habitat. A structure that can be used efficiently throughout its life cycle should neither be left too long without occupants nor should it be used extensively without the supervision and sustentation it requires. Striking this balance can go a long way.

\section{ANALYSIS}

Considering the abovementioned parameters, this analysis is compared against a qualitative 'best practice' and two Case Studies: The Colosseum, Rome, and The Bramall Lane Stadium, England.

Table 1: Analysis of Case Studies against Best Practices

\begin{tabular}{|c|c|c|c|c|c|}
\hline & Capacity & Socio economic impact & Other Purposes & $\begin{array}{l}\text { Glamour vs quality } \\
\text { essentials }\end{array}$ & $\begin{array}{l}\text { Change over } \\
\text { time }\end{array}$ \\
\hline Best Practices & $\begin{array}{l}\text { Ranging from } \\
30,000 \text { to } \\
50,000 . \\
\text { Pertaining to } \\
\text { sport } \\
\text { popularity }\end{array}$ & $\begin{array}{l}\text { Involve the people's } \\
\text { larger interest, especially } \\
\text { in commercial sports. } \\
\text { Maintain the sanctity of } \\
\text { rules in competitive } \\
\text { sport }\end{array}$ & $\begin{array}{l}\text { Space should be } \\
\text { utilized for other } \\
\text { reasons after } \\
\text { event. Be it } \\
\text { commercial or in } \\
\text { development of } \\
\text { said sport culture. }\end{array}$ & $\begin{array}{l}\text { Glamour in itself } \\
\text { becomes an essential } \\
\text { for it contributes to } \\
\text { the crowd workand } \\
\text { intrigue of patrons. }\end{array}$ & $\begin{array}{l}\text { Dependent on } \\
\text { how relevant } \\
\text { the sport has } \\
\text { stayed over } \\
\text { time. }\end{array}$ \\
\hline $\begin{array}{l}\text { Colosseum - } \\
\text { Rome, Italy }\end{array}$ & $\begin{array}{l}50,000- \\
80,000 \\
\text { spectators }\end{array}$ & $\begin{array}{l}\text { - One of the first } \\
\text { structures with the } \\
\text { intention of social } \\
\text { gathering } \\
\text { - Connect b/w monarch } \\
\text { and people } \\
\text { - Common intention of } \\
\text { recreation }\end{array}$ & $\begin{array}{l}\text { - Rented as houses } \\
\text { and workshops } \\
\text { - Took over as a } \\
\text { fortified castle } \\
\text { - Church and } \\
\text { chapel }\end{array}$ & $\begin{array}{l}\text { - The kind of sports } \\
\text { hosted over time were } \\
\text { always by monarchs } \\
\text { and grandeur equated } \\
\text { to power } \\
\text { - Sturdyand spacious } \\
\text { structure specific to } \\
\text { sport. }\end{array}$ & $\begin{array}{l}\text { - As blood } \\
\text { sportsare no } \\
\text { morea } \\
\text { commonality, } \\
\text { the space has } \\
\text { been } \\
\text { repurposed for } \\
\text { other reasons }\end{array}$ \\
\hline $\begin{array}{l}\text { Bramall Lane } \\
\text { Stadium - } \\
\text { Sheffield, England }\end{array}$ & $\begin{array}{l}32,050 \\
\text { spectators }\end{array}$ & $\begin{array}{l}\text { - One of the pioneers in } \\
\text { professional sports } \\
\text { - }\end{array}$ & $\begin{array}{l}\text { - Hosted cricket } \\
\text { games as well } \\
\text { - Home to one of } \\
\text { the oldest FA in } \\
\text { the world }\end{array}$ & $\begin{array}{l}\text { - Growing need for } \\
\text { glamour as per the } \\
\text { popularity of sport. } \\
\text { - Essentials are being } \\
\text { refined as per } \\
\text { improved rules and } \\
\text { guidelines. }\end{array}$ & $\begin{array}{l}\text { - Developed to } \\
\text { support the } \\
\text { sport } \\
\text { - Still hosts } \\
\text { World cups and } \\
\text { FA } \\
\text { tournaments. }\end{array}$ \\
\hline
\end{tabular}


As per the table, we observe that a larger capacity of the Stadium is a common feature, owing to the popularity of the activity. Not only does the large viewership maintain the spirit of the sport, but the space capacity also allows the multipurpose of the stadium for other reasons.

The socio-economic impact of both the structures is great and life-altering in their respective periods. Both structures have contributed to bridging the class divide and normalizing societal practices of various facets.

The Colosseum and Bramall Lane are no exceptions to being a multipurpose space, contributing to temporary housing, medical camps during a crisis, and even extra revenue streams through rent-outs for events and concerts. The Bramall Lane hosted Bruce Springsteen in the July of 1988, a largely spoken about event, even today.

The Glamor vs. quality essential have an evolving meaning, for glamour itself became essential in sports viewership over time. Noticed in the audience of these two case studies, both Blood Sport and Football have a very zealous fanbase, who are loud and vocal with their support to the teams. The glamour quotient will always remain as a medium to communicate this. Nonetheless, the quality essentials have never been compromised, for they have always been the deciding factor towards coveted design decisions. The quality has only increased and the stadiums have always met it. One can even go as far as to say that the quality of the essential aspects of the stadium is an attribute to the glamor exhibited in celebration of the events.

Change over time, however, has two things to consider: The relevance of the sport itself over time and the stadium's usage, structural integrity, and maintenance over the same period. With the Colosseum, we see that blood sports declined and any current day practice of it is in the preservation of the culture and heritage. But the second study focuses on Football and cricket, which are currently the most-watched and enjoyed sport across the whole world. Due to the large patronage, there are constant league matches and tournaments throughout the year, keeping these stadiums in use for the most part.

\section{INFERENCE AND CONCLUSION}

Architecture has always been driven by the need for better and it is no different with sports. The popularity of the game allowed bigger capacities and further the quality of interiors and accommodation seen over time. Grandeur has always been a popular association with sport, simply because of how it brings people together. It has been a way to show pride and devotion to identities such as nationality and heritage.

The trend of Stadium design though is a more recent direction of efforts, for it has become popular only in the last few decades. The custom of practical designs has been replaced by the need for luxury and comfort of the users. The clientele, majorly falling within the 18 to 34 age categories, prefer attendance of sports events to be an extraordinary experience filled with emotions and great accommodation.

Another observation that remains prominent is how the standard areas and practices of the sporting industry have a long history of their own. The reason why the regulatory bodies are more directed towards the maintenance of this standard and not the experimentation and altering of these standards is that these are time-tested and set an evaluation benchmark across time.

The evolution of sports as an industry and their facilities has been an extensive exercise, for we have seen how cities and districts can grow enormously due to the presence of such an establishment.

It is imperative to factor in, not only the future of a sport but to understand the reason behind the growth of a sport, to develop a sports structure. The benefits it has to the community at large are both tangible and intangible tendencies. The grit and drive in the opinion of people and how sportsmanship captures this essence have always been the foundation of a good sporting complex. The accommodation of the viewer, their experience in the stadium (before, during, and after the game) is observed to be constant and any and every change in the design aspect can be directly related to that.

While economists have questioned whether the pros outweigh the cons, sports facilitate have benefited cities and the surrounding areas in terms of landscape and recognition. Sports have always recognized cultures that have prioritized them, amplified by the Architecture that captures the value it presents, for it is not just about winning a game of predetermined rules, but how these spaces allow the free expression of competitive spirit to be exhibited by the sportsmen of the people at large, as largely observed in the Barcelona, New York and the likes of many such cities and states. 


\section{REFERENCE LIST}

A TOUCH OF ROME - The Colosseum Educational Page. (2021). A TOUCH OF ROME. https://www.atouchofrome.com/colosseum.html

Barghchi, M., Bt Omar, D., \& Salleh Ama, M. (2009). Sports facilities development and urban generation. Journal of Social Sciences, 5(4), 460-465. doi:10.3844/jssp.2009.460.465

By The Newsroom. (2018, February 21). In pictures: The evolution of Sheffield United's Bramall Lane stadium through the years. The Star. https://www.thestar.co.uk/news/pictures-evolution-sheffielduniteds-bramall-lane-stadium-through-years-436973

Chapin, T. S. (2004). Sports Facilities as Urban Redevelopment Catalysts: Baltimore's Camden Yards and Cleveland's Gateway. Journal of the American Planning Association, 70(2), 193-209. https://doi.org/10.1080/01944360408976370

Colosseum | The Roman Colosseum at UNRV.com. (2010). UNRV - Roman History. https://www.unrv.com/culture/colosseum.php\#:\%7E:text=Why\%20was\%20the\%20Colosseum\%20Buil t,little\%20more\%20extreme\%20and\%20bloody.

Culley, P., \& Pascoe, J. (2015). Sports facilities and technologies (1st ed). Routledge.

FIFA World Cup Finals Stadiums Then \& Now. (2018, June 20). [Video]. YouTube. https://www.youtube.com/watch?v=B0k-fp0barQ

HISTORY OF SPORTS AND GAMES. (2001). Historyworld.Net. http://www.historyworld.net/wrldhis/PlainTextHistories. asp?groupid=2271\&HistorylD=ac02>rack=pthc

IvyPanda. (2020, March 12). Football Impact on England's Culture. Retrieved from https://ivypanda.com/essays/football-impact-on-englands-culture/

Karikari, B. (2020, November 19). Sports Stadiums Past and Present. Allsite Structures. https://allsitestructures.com/history-sports-stadiums/

Kiuri, M., \& Teller, J. (2015). Olympic Stadiums and Cultural Heritage: On the Nature and Status of Heritage Values in Large Sport Facilities. The International Journal of the History of Sport, 32(5), 684-707. https://doi.org/10.1080/09523367.2015.1037745

Maassoumeh, B., Omar, D. B., \& Aman, M. S. (2009, April 1). Sports Facilities Development and Urban Generation. ResearchGate.

https://www.researchgate.net/publication/41025333_Sports_Facilities_Development_and_Urban_Gen eration

Medicine in the war zone. (2019, January 19). Science Museum. https://www.sciencemuseum.org.uk/objects-and-stories/medicine/medicine-war-zone

Newsome, T. H., \& Comer, J. C. (2000, February). Changing intra-urban location patterns of major league sports facilities. The Professional Geographer, 52(1), 105-120. Retrieved from www.ux1.eiu.edu/ jadavis2/Sports/Sports\%20Venues.pdf

Plunkett Research. (2013). Introduction to the sports industry. Retrieved from http://www.plunkettresearch.com/sports-recreation-leisure-market-research/industry-trends

Robertson, R. (2010). The economic impact of sports facilities. The Sport Digest. Retrieved from http://thesportdigest.com/archive/article/economic-impact-sports-facilities

S. (2018, January 29). Present status of sports infrastructure in India and necessary recommendations for further development. Sports Venue Business (SVB).

https://sportsvenuebusiness.com/2018/01/29/present-status-sports-infrastructure-india-necessaryrecommendations-development/

Sawyer, T. H. (2009). Facility design for health, fitness, physical activity, recreation, and sports facility development. Sagamore Publishing. Retrieved from http://www.sagamorepub.com/files/lookinside/6/pages-facility-pd12th.pdf

Spencer, S. (2020, March 20). "The English Game" on Netflix: The True Story Behind the Julian Fellowes Football Drama. Newsweek. https://www.newsweek.com/english-game-netflix-true-story-footballsoccer-julian-fellowes-arthur-kinnaird-fergus-suter-1493204 
Taraszkiewicz, K., \& Nyka, L. (2017). Role of Sports Facilities in the Process of Revitalization of Brownfields. IOP Conference Series: Materials Science and Engineering, 245, 042063. https://doi.org/10.1088/1757-899x/245/4/042063

Technical Note Ten: Facility Location [Technical Note]. (2003). Retrieved from www.ateneonline.it/chase2e/studenti/tn/6184-7_tn10.pdf

Wikipedia contributors. (2021, April 18). History of sport. Wikipedia. https://en.wikipedia.org/wiki/History_of_sport

Wikipedia contributors. (2021b, April 21). Bramall Lane. Wikipedia. https://en.wikipedia.org/wiki/Bramall_Lane

Wilkins, Dominique, "The Effect of Athletic Stadiums on Communities, with a Focus on Housing" (2016). International Development, Community and Environment (IDCE). 88.

World Economic Forum. (n.d.). Role of Sports in Society [PDF]. Retrieved from https://members.weforum.org/pdf/GAC/issue_descriptions/RoleofSportsinSociety.pdf

Zetlin, L. (2016, July 13). Stadium | architecture. Encyclopedia Britannica. https://www.britannica.com/technology/stadium 